\title{
5 Untying the Climate-Development Gordian Knot: Economic Options in a Politically Constrained World
}

Jean-Charles Hourcade, P. R. Shukla, and Sandrine Mathy

Climate policies must deal with a contradiction generic to global environment policies: as was recognized as early as in 1972 at the UN conference on Human Environment at Stockholm, the participation of developing countries is essential. The current emissions of developing countries are also significant. If the trend continues, the future share of global emissions from developing countries will be even larger. However, developing countries do not yet see the need to cooperate because they perceive environmental issues to be a form of Malthusianism. Thus, despite repeated calls for sustainable development at Rio (1992), the negotiations for framing a climate regime have remained disengaged from the debates on how to embark on sound development paths, thus tying a Gordian knot through a succession of misunderstandings.

This unhappy turn in policy talks is all the more grave as the timing of the climate change issue is inopportune for developing countries. The increasing attention to the climate change phenomenon has coincided with a period in which many developing countries are experiencing rapid economic growth and in which global power equations are changing (military power, globalization of world markets, and control over natural resources). No sword of a present-day Alexander can cut this 
knot tied by history. The aim of this chapter is to pick out the threads that, when pulled, may untie the knot.

\subsection{Intellectual Sources of North-South Misunderstandings, 1988 to 2005}

It is apt to recall the G7's paradoxical haste, three years after the first predictions of global warming by three-dimensional climate models, to bring to the diplomatic agenda an affair for which its members had born a huge historical responsibility. This attempt cannot be explained without regarding a broad geopolitical reshaping of the petroleum game by the emergence of a large block of developing countries as major consumers in the twenty-first century (Schlessinger 1989).

The momentum to initiate a cap and trade architecture did not come from the deployment of an ex ante full-fledged vision; it was rather the outcome of a succession of diplomatic faits accomplis (Bodanski 2001), the most important being the adoption at Berlin (1994) of a quantity-based approach to create an incentive system that would embrace all countries and sectors. The decision rested on the economic notion that a single price of carbon worldwide is essential to minimize the costs of meeting a global target and to prevent distortion in international competition. After 1992 the unpopularity of carbon taxes left the cap and trade system the sole contender for this purpose. Against the reluctance of some quarters 
in the European Union that wanted caps with limits to trade, this system was advocated as best meeting the criteria of cost-effectiveness, environmental integrity, universal participation, and flexibility vis-à-vis national sovereignty.

On the North-South question, the cap and trade system, as argued by Grubb regarding negotiating targets (1989), had the advantage of organizing large enough North-South transfers to induce a significant commitment by the South in the short term. The commitment of the South would not adequately materialize, however, as the principle of common but differentiated responsibilities (article 3.1 of the UNFCCC) led to the cautious decision that only developed countries would adopt binding commitments in the first period. But the silence on targets for the developing countries beyond 2012 had the perverse effect of treating them as pure spectators of the intra-annex-B debates (target setting and a supplementarity squabble) as if the South should be content with their absence of commitment, or avoidance of damages, thanks to the Kyoto Protocol, and obtain some financial and technological gains through jointly implemented abatement projects. The silence about the developing countries' future commitments and the disengagement of climate negotiations from other global governance issues (energy, trade, and technology) brought skepticism if not distrust.

As became duly clear from subsequent events, the cap and trade option could not be a magic bullet for either side: 
- The US Senate (Byrd-Hagel resolution 1997) demanded developing countries to agree to "new specific scheduled commitments to limit or reduce greenhouse gas emissions." The large asymmetry of carbon constraints for developing economies was rejected by the no vote without participation principle (Bodansky 2001).

- On the final day of COP3, the G77 plus China concurred that until the question of emission rights and entitlements is not addressed equitably it will not be possible to have emissions trading (G7 and China 1997). The concern was unfair future quota allocations but also the will of emerging economies to be politically engaged in the debate.

Why the diplomatic momentum was not altered as a result is a complex story. It may be due to the prevalence of misinterpreted economic communications. Between COP3 and COP6, supporters of the Kyoto Protocol could not surmount the political divergences over the technical modalities of cap and trade enforcement and make credible offers to developing countries.

\subsection{The Tabula Rasa Myth}

The science of economics has evolved through uneasy journeys, among them routes of neglect, distrust, misuse, and abuse, the same as in any other science. Contributing to the present confusion is that optimal tools in a first-best world can be far from 
optimal if applied without caution in a second-best world. In the real world there are no tabulae rasae; countries are full of imperfections, the hallmarks of which in conditions of underdevelopment are the existence of incomplete and fragmented markets (multiple discount rates, unequal marginal costs across sectors and regions), weak policy regimes, poor governance, under protected property rights (land, technology, and IPRs), and dual economies in perpetual reformation. Carbon pricing for the so-called second-best world has two main consequences.

First, the carbon price signal in countries experiencing multiple rapid transitions and technological shifts is swamped by noise from other signals. One possible perverse effect is that the carbon price will increase carbon emissions as the switch is made to carbon-intensive nontraded energy resources (Sagar 2005) and will initially also reduce the electricity access of the rural sector. This is not just a matter of a relative price to service ratio. Rural markets have informal lending mechanisms that provide credit to small enterprises and households with high interest rates in a context of low labor rates due to the lack of firm wage contracts. The benefits associated with energy resources from a formal market therefore do not exist. While benefits could be introduced by altering baseline parameters such as interest rates and wages, these mechanisms are beyond the scope of climate centric policy.

Second, the development benefits of carbon trading are uncertain; this is not only because annex-B countries will not accept allocation rules generating large 
external transfers; they recognize that the revenues from carbon exports may not materialize as higher income for the exporter. Indeed, to exploit the full potential of carbon export for a given world carbon price, the domestic energy price has to increase more, in relative value, in most developing countries than in the European Union and in the United States (four and two times more respectively in India); the negative income effect would be such that it may not be fully compensated by the inflow of carbon revenues especially in countries with market distortions, large inequalities, and political constraints to redistribution (Ghersi et al. 2003). To avoid the dampening of growth, governments would then export only that fraction of the export potential for which these adverse effects can be compensated by an efficient recycling of carbon revenues. So the availability of cheap carbon in developing countries may be significantly lower than suggested by partial equilibrium analysis.

This lack of trust in carbon credits could be amended by short-term benefits from the CDM. Unlike the Kyoto joint implementation program, it would mean a sudden change in operation with an inversion of priorities that would more credibly place sustainable development in the first rank and the facilitation of annex-B commitments in the third. But despite a recent rise in the number of projects, participation has been limited because of contradictory requirements: environmentalists seeking an environmental outcome additional to the baseline and funding agencies' reluctance to provide additional support from the fear of diversion of overseas development assistance funds for the environment. As a result both 
parties have put off funding (which remains to be tapped) and have excluded infrastructure projects from the CDM because the "avoided" emissions are difficult to ascertain.

Barring the pursuit of a Brazilian type of compliance fund or an extension of the share of proceeds on mechanisms that could provide funding complementary to carbon revenues, the developing countries have chosen to interpret the offer of annex-B countries as an empty pledge that would result in pawning the real present welfare for the unreal future gains.

\subsubsection{Burden Sharing and Normative Equity Principles}

The equity issues relating to the climate debate were obvious from the outset. So it is remarkable that economists remain silent about the theoretical framing of fairness on emission rights and have restricted themselves to studying the outcomes of competing ethical intuitions.

The most challenging of these intuitions is the equal per capita distribution of emissions rights (Agarwal and Narain 1991). Arguably, such an allocation may be inequitable. Individuals live in very different ambient climates, with different spatial constraints and energy accesses (Godard 2000; Neumayer 2002), but the rhetorical proximity between the notions of equity and equality has transformed this principle into a political icon for those who consider the grandfathering principle an 
environmental colonialism. This icon was strong enough to be retained at Marrakech in 2001.

There could not arise anything but intense debate. Grandfathering is widely considered to underlie the international agreements on, for example, multilateral fishing quotas (Sterner 2002), milk quotas in Europe (Burton 1985), and the $\mathrm{SO}_{2}$ regime in the United States (Joskow et al. 1999). The real basis is the ethical legitimacy of any new environmental regulation as a renegotiation of a social contract, and it is all the more fair to account for interests vested under the existing contractas previous generations were not informed of the consequences of their behaviors (Claussen et al. 1998). But distributing rights for the future use of the atmosphere based on grandfathering would lead to inequitable future contracts that the developing countries cannot accept.

The search for a consensus on such explicit principles has turned into harsh polemics, the two pragmatic positions being (1) starting the rules from grandfathering and supporting a contraction and convergence process (Meyer, 2000; Ghersi et al. 2003) toward equal per capita emissions in the long run or (2) creating rules that refer (at least indirectly) to the ability to pay in combination with other criteria (Jacoby et. al. 1999). Also explored have been a triptych approach (Phylipsen et al. 1998; Groenenberg et al. 2000; Jansen et al. 2001) and proposals from Norway (1996), Australia (1997), and Iceland (1997) at the Ad hoc Group on the Berlin Mandate. 
Given the conflicts of interests, no rule can ensure consensus. The uncertainty about the links between the levels of the emissions caps and the carbon prices, and their macroeconomic consequences, is sure to generate fuzzy contracts. The insinuation is that countries will have to accept one of these positions despite their divergent views. In a systematic review Lecocq and Crassous (2003) show country preferences related to allocation rules are very unstable and conditional on baselines assumptions and time horizons. Both China and Europe, starting from different emission levels,could reject rules with high weights to convergence toward 2030 but accept the rules if the weights are for only the immediate post-2012 period. It could be argued that setting targets for every five years creates a learning curve, but that addresses the issue only marginally. The possibility of drastic revisions to the allocation rules is rather limited by the political costs of reversing any diplomatic fait accompli and by the risk of undermining the dynamic efficiency of the system, since countries may then lower their abatement efforts in order to renegotiate lax targets for future periods (Helioui 2002).

Added to these difficulties are two political obstacles. First, governments face the task of trade-offs among various assessments criteria: maximizing the funds inflow from carbon trading and minimizing the costs for the low-income classes may indeed not lead to the same vision of the burden. Second, contradictions arise in crosscountry comparisons: poor citizens of a rich country contribute far less to global warming than do rich citizens of developing countries. 
In fact the big problem is an impasse on what constitutes a fair burden, as would include forms of trade-offs within a wide development agenda. Political acumen would have made this obvious but for the vulgate of Kantian ethics used in international meetings that have overshadowed the Machiavelli's idea that states are cold-hearted monsters designed to defend the selfish interests of their constituents. The only way out is to return to Pareto-improving policies; moving afar from the focus on "burden sharing" and "property rights entitlement." Emissions quotas are then no longer rights but transitory allowances, and the relevant question is under what conditions cap and trade can be used as a tool for removing barriers to development. This re-framing does not eliminate debates about equity and responsibility; it puts them in the perspective of reshaping development instead of capping it. The challenge is to demonstrate that postulating the existence of win-win options is not another wishful way to reconcile contradictory interests.

\subsubsection{Aligning Development Pathways and Long-term Climate Change}

\section{Policies}

\section{An Intellectual Discipline: Starting from the Suboptimal and Real Baselines}

The common practice of projecting secular growth baselines (often optimistic for reasons of political correctness) has hampered the detection of synergies between climate and development despite attempts through environment policies to alter this 
trend. It therefore is appropriate to start by delineating the baselines that incorporate barriers to the realization of a growth potential. This was the intellectual tenor at Stockholm (1972) where concern over disruptions of local environments opened discussion ${ }^{1}$ on the perverse effects of ongoing growth patterns (damage due to choice of equipment, structural unemployment, disregard of basic population needs, erosion of soil).

The concern voiced at Stockholm 1972 needs to be revisited today in terms of the evolving linkages between capital scarcity, infrastructure requirements, and social dualism. Cumulative energy investments between 2001 and 2030 are projected to reach 2.2 T\$ in China, 2.1 T\$ in the rest of Asia, and 1.3 T\$ in Latin America (IEA 2003). Fay and Yepes (2003) estimate that from 2005 to 2010, 6.7 percent of the GDP in Asia and 5.5 percent in Africa will have to be invested in energy, transportation, water distribution, and sanitation infrastructures. Since 40 to 60 percent of savings will still have to be invested in buildings, funding infrastructure investments will remain critical for reason either of capital scarcity (Africa's saving rate is 8 percent of GDP) or of inefficient allocation in countries with high savings. The latter may in addition not sustain a capital-intensive growth when their savings rates decline such as in China where the inversion of age pyramid between 2020 and 2030 is expected to cause a decline of savings from the present 40 to 8 percent in 2050 (INGENUE 2005). An analogy may be the debt trap of Brazil in the late 1970s when 30 percent of the debt was from investments in the energy sector. Low savings 
can curtail infrastructure programs and enhance resource conflicts between populations with very different accesses to energy, water, and transportation.

Managing energy demand has in fact become more critical as energy security is being more and more perceived as a prime development objective by nations competing for resources in an era of sustained volatility of energy prices. Recent trends only confirm the warnings of the World Energy Conference (WEC) in 1979, that the emergence of developing countries as major oil and gas consumers will be a source of major world tensions after 2000. Ten years later, in 1989, the WEC was reminded of this prognosis in Montréal by James Schlessinger. Added to the controversies over the timing of peak oil production, the conventional oil reserves have remained increasingly concentrated in politically sensitive regions.

The question for a climate regime set on tackling energy-related obstacles is to what extent the value of carbon can help developing countries move upward on the production frontier. In principle, the creation and sharing of a carbon benefit can produce a leverage effect by enhancing the profitability of foreign investments, on the one hand, and by compensating the transaction costs of Pareto-improving domestic policies, on the other. As we explain next, the mechanism to activate win-win options is not so remote; it indeed exists.

\section{Development and Climate Synergies: Illustrations from India}


The counterargument to the notion of no-regret policies that enhance both environment quality and economic income is that where a no-regret potential exists, it will be tapped anyway. The different examples of this section provide a perspective that is not restricted to the instruments and technologies of the 1990s J Jaffe and Stavins 1994; IPCC 1995); they show that climate policies can facilitate an upward shift in the development baselines with the new baselines presenting even more potential for decarbonization policies.

\subsubsection{Conjoint Market for Local and Greenhouse Gas Emissions}

Local air pollution reaches highest levels in large developing countries as they undergo transitition to urbanization and industrialization. The local air pollutants and greenhouse gasses, which are often emitted conjointly, accumulate and create climate changes but also health problems for humans affecting their health and development. In India, for instance, 70 percent of coal consumption is by the electricity sector (CMIE 2003) with the emissions being mostly sulfur dioxide $\left(\mathrm{SO}_{2}\right)$. In fact, as of 2000, two-thirds of India's $\mathrm{CO}_{2}$ and $\mathrm{SO}_{2}$ emissions come from 500 large point sources, of which 82 are coal-based power plants and the rest mostly transport, steel, and cement manufacturing (Shukla et al. 2004).

Yet, although the electricity sector in India lacks efficient emissions controls, opportunities exist for creating conjoint emissions control mechanisms. Interestingly the relationship between sulfur and carbon control is asymmetric (Pandey and Shukla 
2002; Garg et al. 2003). Cost-effective measures like better combustion efficiency and a fuel switch from coal to gas could reduce sulfur emissions to greater extent than carbon emissions, but the cost-effective sulfur control measures like the use of clean coal technologies or low-sulfur diesel fuel would have little impact on carbon emissions. The local pollution did draw the attention of national policy makers. However, the sequencing of $\mathrm{SO}_{2}$ and $\mathrm{CO}_{2}$ markets proved to be suboptimal because the single measures to control local pollution failed to net the co-benefits of concurrent $\mathrm{SO}_{2}$ and $\mathrm{CO}_{2}$ mitigation. There is nevertheless scope for a policy designed to align both markets and optimize co-benefits. At a low carbon price of $\$ 20 / \mathrm{tCO}_{2}$, the aggregate mitigation cost over the next 25 years in the conjoint system would be lower by $\$ 400$ million compared to under the two separately operating markets. Further the conjoint system could deliver $520 \mathrm{Mt}$ of additional $\mathrm{CO}_{2}$ mitigation and thereby add $\$ 2.6$ billion to the carbon benefits (Menon-Choudhary et al. 2004). Correcting such asymmetry and incongruent actions typically demands institutional financial arrangements at the national level that should benefit from a climate regime.

\subsubsection{Synergy of Electricity Market Reforms and Revenues from Carbon}

\section{Trading}

After India's electricity sector reforms in early 1990s the sector became more dependent on domestic coal, as hydropower was confronted by high capital costs 
and the building of large dams besieged by protest movements and interstate water disputes. The barriers to hydro and the bottlenecks in coal supplies caused the electricity sector to shift to gas in a market where the combined cycle gas technology offered advantages of low investment, short gestation, and low local emissions. Despite this shift, the carbon content of electricity increased, and the hydro share of the market continued a secular decline (Shukla et al. 2004).

Globally energy reforms also remain centered on fossil fuel. However, in 2002 came the India Vision 2020 (Planning Commission 2002) plan, which proposed an alternative best-case scenario (BCS) that could bifurcate the sector's development. The Vision is directed toward an alternative pathway that includes modernizing existing plants, early adoption of advanced technologies, improved T\&D efficiency, energy conservation, regional energy cooperation, and higher shares of hydro and renewable energy. Carbon emissions in 2020, under BCS, are projected to be $81 \mathrm{MtC}$ below the BAU (822 MtC cumulated up to 2020).

In the case of India there could be envisaged a sector-based agreement by which the carbon abatements could be sold on the world carbon market. ${ }^{2}$ The implementation of BCS policies (including carbon taxation and subsidies to renewable technologies) would have three conjoint effects: (1) lower profitability of coal plants and increased profitability of gas and renewable energy, (2) an inflow of foreign capital due to the relative profitability of investment in the sector and the lifting of barriers to foreign investors, which would replace part of the Indian investment in the power sector 
in the reference scenario, and (3) the ensuing domestic investment redirected toward other sectors. By this mechanism the carbon revenues would have a leverage effect whose main determinants would be (with a given value of carbon and regardless of the lower public expenditures to compensate local externalities):

- The gap between the social marginal profitability of energy investment with or without BCS policies (including the taxation on coal).

- The gap between the social marginal profitability of energy and nonenergy investment.

- The share of foreign investments as a function of a foreign investor's internal return rate.

With a value of $10 \$ / \mathrm{tC}$ and a linear increasing tax level reaching 30 percent of the coal price in 2035 , the mechanism would generate an additional income of US\$1.6 to US\$7 for each dollar of carbon credit depending on assumptions of marginal productivity in the power sector and in the rest of the economy (see Mathy et al. 2001).

Climate Regime and the Co-benefits from Regional Cooperation Regional cooperation, as promoted by the principle 9 of the Rio Declaration on the Environment, may be supported by compelling arguments. However, countries are so diverse in terms of institutional capacities and political structure that deploying 
complementarities can become a very complicated business. In the South Asia region, ${ }^{3}$ for example (Nair et al. 2003; Heller and Shukla 2004), there are diverse endowments in energy resources—-with coal in India, gas in Bangladesh, hydro potential in the Himalayan nations of Bhutan and Nepal, and strategic location of Pakistan for the transit routes linking South Asia with the vast gas and oil resources of Central Asia and the Middle East. Still there is little energy and electricity trade in the region.

Assuming a regional cooperation, Heller and Shukla (2004) show that the energy trade would yield direct economic benefits due to energy savings from improved fuel and technology choices and would lower investments in energy supply. The benefits are valued at US $\$ 319$ billion from 2010 to 2030 . The economic growth of the region would increase by 1 percent each year, benefiting an overwhelming number of the world's poor. Such cooperation would in addition deliver a cumulative carbon saving of 1.4 GT for the period 2010 to 2030 , or 70 percent of the global mitigation by the 1997 Kyoto Protocol standard over the estimated baseline emissions (Chandler et al. 2002), including the original commitment by United States at Kyoto. The energy changes would also reduce loads of $\mathrm{SO}_{2}$ in the region by nearly 30 percent. In addition the balanced hydro development would yield spillover benefits that are synergistic with adaptation needs, among which are enhanced water supply and flood control.

Infrastructure, Development and Climate Vulnerability Infrastructures designed to 
withstand and long endure the variabilities of current climate conditions can render them vulnerable to climate change. A good example of such long-lived assets is the recently constructed Konkan railway. Located on the coastal strip of land bounded by the Sahayadri hills and Arabian Sea on the western coast of India, the Konkan railway covers a distance of $760 \mathrm{~km}$. It costed US\$745 million to build and commenced operations in 1998. The railway passes through a mountainous region and has 179 major bridges, 1819 minor bridges, and 9 tunnels exceeding $2.2 \mathrm{~km}$ (KRCL 1999). Climate projections for the area (Mitra et al. 2002) show an increase in the mean and variability of the distribution of the key climate parameter of rainfall, the impact assessed in days with more than $200 \mathrm{~mm}$ of precipitation. Besides rainfall, the development pattern was considered as affecting the geology, soil structure, and vegetation cover in the region and also landslides.

In the monsoon season the train schedules are disrupted by waterlogged tracks and landslides; 140 such incidences were reported in 2000 (Kapshe et al. 2003). The railway company spends 6 percent of its revenue on repair and maintenance, and 20 percent of this expenditure is for minimizing the severity of such climate-related incidents. Future disruptions are expected to be greater because of the compounded effect of climate change and an aging railway infrastructure. It would be prudent to protect the infrastructure but adaptation measures like improving climate predictions, reinforcing the vulnerable points, and making maintenance regimes more frequent require committing more public expenditure, which cannot be fully recovered by taxes in India. This case is representative of many such cases in the developing world that 
call for a climate regime that can deliver cumulative assistance in the form of development, mitigation, and adaptation co-benefits.

\subsection{The Kyoto Architecture Reinterpreted, Amended, Completed}

The complexity of climate and development nexus may be an argument for what Jacoby metaphorically calls a favela regime (Jacoby 2005), namely a self-organizing process instead of a hopeless pursuit of some grand architecture (Bodanski 2003). But favelas turned more often into self-reproducing pockets of violence, slavery, and poverty than into an innovative urban scheme. The transition to a common architecture may fare better if it is instead modest and flexible.

The main purpose for a common architecture is that the key sectors for the climate control are capital intensive with investments spanning over decades. Early and credible signals launched in this direction should therefore avoid lock-ins to carbon-intensive systems. This does not mean a full-fledged architecture by 2012 but the initiation of a process that can gain momentum and converge on some viable system. The flaws of Kyoto have been extensively pointed out (Victor 2001), but there are two reasons why Kyoto remains the framework that can support such a convergence. The first is political: it is diplomatically discomforting to write off a treaty ratified by all countries but one (since the ratification by Australia in 2007), as is 
now the geopolitical game. The second is the for lack of anything better argument, that no proposed substitute provides the same potential to untie the developmentenvironment knot.

An internationally coordinated carbon tax (Cooper 1998; Nordhaus 1994) would confront the same equity issue as a cap and trade system (higher marginal welfare loss for a given carbon price in low-income populations) while not providing ways to compensate abatements through generous allocations of quotas (Chichilnisky and Heal 2000). In developing countries the middle class represents a small share of population compared with low-income classes, and this makes it difficult to operate emission compensation domestically through a reshaping of fiscal systems. Net foreign inflows may be helpful, however, and whether they come from overseas aid at a similar order of magnitude as the transfers from carbon trading is, to say the least, open to discussion.

An acceleration of R\&D efforts disconnected from any economic signal may be a technological push, a model that works only for large scientific ventures (space exploration, conventional electronuclear fusion, etc.); a technological push is less effective when the innovation is to be deployed in hundreds of end-use services and under large controversies about the most promising technologies on the supply side. The six-country initiative, called the Asia-Pacific Partnership for Clean Development and Climate, proposes cooperative voluntary actions for the development, deployment, and transfer of technologies to meet these countries' own development 
objectives. The question remains nevertheless whether such cooperation can deliver its full potential in the absence of any economic signal.

In the absence of anything better, the question might be what reinterpretation and amendment of the Kyoto Protocol would alleviate the current flaws? There is no good answer other than to put the cap and trade system into a new paradigm of climate negotiations.

\subsubsection{Shifting the Bargaining Paradigm, Shifting the Status of the Climate}

\section{Regime}

In the reordering of the world since Kyoto, there have been far-reaching structural transitions in major developing countries that are sure to alter the dynamics of new rounds of any international negotiation. These countries' enrichments, of course, create ground for demanding from them acceptance of emissions limitations; their response will depend on whether they will consider that investing in backbone infrastructures will lock them into an unsound development pattern, and whether they will grasp the dire implications of climate change issues for energy security (Heller and Shukla 2003). The initial national communications to the UNFCCC of a number of developing countries suggest such an alignment of climate and development objectives, and their governments have made multiple declarations in that direction: Millennium Declaration at the UN Millennium Summit (2000), the Johannesburg Declaration at the World Summit on Sustainable Development (2002), and the Delhi 
Declaration on Sustainable Development and Climate Change at the Eighth Conference of Parties (2003).

The outcome will depend on an acceptance of so-called offers made by the North, but realistically, the timing is inconvenient; it should be recognized that climate action is more urgent today than in 1992 and 1997. Any significant transfers to developing countries in climate action have to be accepted as threatening jobs. This is why developed countries should be serious about why they want climate policies: Is it solely for environmental reasons? Or is it because of the political instability that climate change could create in areas of low adaptativity? Or is it part of the geopolitics of energy?

A recent declaration by the G8 suggests a broadening of the negotiation paradigm :"We will act with resolve and urgency now to meet our shared and multiple objectives of reducing greenhouse gas emissions, improving the global environment, enhancing energy security and cutting air pollution in conjunction with our vigorous efforts to reduce poverty" (G8 declaration, July 2005). Climate policies could be a unifying force in a transformation of economic globalization into a mutually benefiting process instead of a devisive one for all nations and thus avert threats on energy security, climate refugees, and local political instability. A big step forward would be to replace negative arguments by positive ones. The demand for infrastructures in developing countries offers a window of opportunity (G8 2005) and 
a type of Marshall Plan as implemented in the 1970s (Carter et al. 1976; Tinbergen 1976; Brandt 1980) could enable the developing world to rise to its full potential.

This new bargaining paradigm has two implications for the role of a climate regime. First, this regime does not pretend to dictate many of the core decisions contributing to the decarbonization of the economy. Instead it views all related policy processes as opportunities to internalize long term signals of the social value of carbon abatements. Second, its architecture is "minimal"; instead of dictating uniform solutions it is - i) flexible enough to crystallize bottom-up initiatives of regional or sector-based cooperation, and ii) integrated enough to prevent the traps of a favela approach.

\subsubsection{Basic Principles for a Minimal Architecture in a Dynamic World}

The Kyoto Protocol provides some insight into how a minimal architecture could secure a flexible relationship between the environmental interests and development. It is also necessary to dispel the notion that any flexible mechanism represents a threat to the environmental integrity of any climate regime.

\section{Using Carbon Prices as Inducement, not as a Unique Driver of Climate}

Policies Decarbonization will depend on a wider range of signals than just the carbon price: interest rates, insurance premiums, certification of clean technologies, tax systems, regulation of the labor market, prices of land and housing, transport costs 
and regulations, and local environmental factors. This is not to minimize the role of carbon prices but to expand the argument, since price is a parameter against which there can be measured climate benefits from an initiative to change behavior.

In this view, carbon revenues do not ensure that additional carbon abatement accrue only from purely climate centric measures as would be the case if the world market could confront factories that specialize in a product with precisely measured GHG emissions,. Indeed, because the Kyoto Protocol only creates a carbon market among countries, ${ }^{4}$ it is up to governments to do the selecting, controlling, and redistributing of emission allowances among sectors, and to apply other policy tools that cannot be exchanged individually on a world carbon market.: ${ }^{5}$ Two examples are the lowered emissions that can result as a by-product of speed limits on vehicles intended for road safety or by the upgrading of regional cooperation in the South Asia in order to save on capital cannot be exchanged individually on a carbon market; they will nevertheless increase carbon selling potential on the world carbon market..

The concept of a world carbon market therefore provides countries with a lot of flexibility to overcome any unique obstacle that the carbon price may pose for them individually. Governments are not forced to increase all their domestic energy prices by the level of the international carbon price; they have the leverage to employ other policy parameters in delivering their domestic objectives or constraints. 


\section{Terms of the Negotiation: Diversified Pledges Aligned on Long-term Price}

Signals A precondition for making cap and trade acceptable to developing countries is to abandon the Malthusianism notion that commitment binds a country to certain emission constraints. This can be done first through diversifying the menu of pledges. Some considerations for global commitments for annex B (and countries reaching an agreed threshold level of a per capita income) might be to not preclude:

- nonbinding global quotas (Philibert and Pershing 2002): countries could export carbon if they meet their targets and not be penalized in case of an overshoot;

- sector-based targets: countries could select sectors whose participation could bring development benefits;

- clean development mechanisms: countries and sectors not yet mature to pledge emission limits could receive further supportive action through participation assistance programs.

The argument for easing the commitment objectives might further be supported by the fact that developing countries are generally not in a position to pledge to or negotiate even the lax quotas that annex-B countries may concede to in order to induce them to comply to limiting carbon emissions. With the option of nonbinding commitments non-annex-B countries might be brought to a good faith dialogue; freed from the fear of economic burden, they may also be interested in 
regulating the system, so that the carbon value and the economic gains they have secured by entering the regime do not get deflated.

Another way around the cap on development may be to base targets on performance criteria rather than on absolute caps for non-annex-B countries. The advantage here is that this limits the risk of volatility in economic growth rates, ${ }^{6}$ so whether fast-growing countries experience an 8 percent growth rate or only 6 percent makes a significant 9.8 percent difference over a five-year period. ${ }^{7}$

\section{Linking Incentives to Comply with Assistance to Developing Countries The}

efficacy of a climate regime should not depend on the credibility of a government's commitment, particularly since many countries (and not just the United States) will not accept a system limiting the sovereignty of their legislative institutions. The European experience of sovereignty transfers is a very specific case, and international affairs will likely remain a matter of pledges and review. The question is how to secure compliance in this regard.

For countries with binding commitments the difficulty is that given uncertainty about compliance costs, good faith governments will commit themselves only to lax targets. To facilitate an accord on ambitious targets, a price cap was proposed in 1997 (Kopp, Morgenstern, and Pizer 2000); operating as a safety valve (the worst-polluting countries would pay an agreed-on price), it would hedge against bad surprises. Although the optimists (i.e., the proponents of ambitious climate 
action) may not be happy with an arrangement where abatement costs are low, a safety valve is secured. A price cap can result in a hybrid system à la Roberts and Spence (1976) where a floor price provides disclosure about the price- quantity relationship and thus guides long-term expectations and facilitates a tightening of the system.

The critics against this idea point out that the parties may not be sanctioned for not fulfilling their "legally binding" objectives. This is symptomatic of a misperception of the notion of "legally binding." Military actions set aside, the only effective sanction in international affairs can ultimately come from economic and political reprisals, but these reprisals depend on other tools of international coordination than climate conventions and will never be activated regardless of any related issues. Without linkages the compliance provisions cannot proceed, as in the Marrakech Accord, beyond allowing de facto an accumulation of environmental debts.

A price cap could add economic "teeth" to the system because missed abatements get paid, and the collected funds are used to restore the environment. Funds earmarked for the environment could provide an incentive for developing countries to participate, as is the case of the Compliance Fund proposed by Brazil (UNFCCC 1997) whereby in the non-annex-B countries the selecting of abatement projects would be through auctions. 


\section{Special Treatment of Energy-Intensive Industries Exposed to Global}

Competition When passing from a general declaration to its implementation as policy, policy makers may face an implicit type of protest from companies in energy and carbon-intensive industries in the form of an argument about asymmetrical constraints in international competition. The risks are often overstated as regards the products markets: the likely impact of carbon prices on production costs are one order of magnitude lower than the large oscillations in exchange rates experienced over the last three decades (Quirion and Hourcade 2004) and the increase in transportation cost operates as a countervailing factor. The risk is far higher in terms of equity in allocations of quotas; though in a closed economy, this can be eliminated by allocating a minor share of quotas for free (Goulder 2004); in an open economy, the risks can be covered by the harmonization of quota allocation rules, especially the share between free allocated and auctioned quotas.

Although it could be argued that there are many other sources of differences in competitive conditions (including wages), the political economics of negotiation amply show that no government is in a position to resist the pressure to protect jobs. The way out is to take stock of the fact that ultimately governments will operate internally a differentiation of targets and carbon prices to households and industry (as they do for energy prices) and can, in this way accept price equalization as an inescapable condition for exposed energy-intensive industry. The potential for conflicts at the WTO is large in this domain, and this is why it may be important to 
rely on international sector-based agreements in the few concerned industries on the quota allocation rules. Since national policies would be charged with endorsing these agreements, most of the concerns about international competition could be addressed.

\subsubsection{Reconciling Long-term Goals and Immediate Pressures from Shifting Context of ODA}

Because the benefits that accrue from decarbonization (carbon revenues, avoided damages) are long term, the political agents may feel blocked by the absence of tangible short-term gains. For countries under urgent pressure to switch to more carbon-intensive technologies (introducing motorized transport for bicycling or animal traction, deforestation to increase food production) short-term action could help prevent future carbon-intensive lock-ins.

Inevitably there will be need for annex-B countries to fashion overseas aid and multilateral financing as climate policy tools to accompany such reforms in non-annex$\mathrm{B}$ countries. The debate framed so far is in terms of avoiding a crowding-out of public aid by transfers submitted with environmental conditionalities. This prospect could be avoided by the provision of additional resources to the carbon-trading regime (price caps, shares of proceeds from carbon trading, taxes on bunkers and international aviation). Indeed how to raise money is far less difficult than to guarantee their efficient 
use in conjunction with other funding mechanisms. This has become all the more complex as developing countries are evolving quickly in very different directions.

Rapidly emerging countries are now main recipients of international private investments. But the quantity and quality responses to the flow of funds are not meeting the corresponding investment requirements on decarbonization objectives. Public funds could be used to provide support for critical project financing and, more important, for public-private technical and institutional partnerships (structural reforms, multilateral agencies, credit exportation agencies, third-party financing). Developing countries whose reduction potentials are only limited volumes of emissions would in this way receive assistance from ODA for the construction of infrastructures and for enlarging basic structural needs.

Climate policies offer the opportunity of adding a quantifiable dimension (the emissions levels) for evaluating ODA efficiency, for disciplining the investor and the host country, and for ensuring quality results for money expended. The monitoring capacity can also be used indirectly by development finance institutions to provide risk mitigation instruments. The PLANTAR project (sustainable fuelwood under the PCF) in Minas Gerais (Brazil) could not obtain any currency risk insurance beyond two years; with carbon finance revenues (US\$ or $€$ denominated) placed in an offshore escrow account, an OECD commercial bank agreed to a five-year loan and the amortization is structured to match expected payments for the CERs. Emission reduction purchase agreements (ERPA) can serve as a type of insurance package that 
can be dedicated to funding project completions. ERPA funds can generate the necessary cash and prevent currency risk, because the lenders must provide the cash up front.

\subsection{Conclusion}

Climate policies cannot be an isolated item on the international agenda. Objectives of environmental integrity present opportunities for engaging developing countries in pro-active climate strategies. The problem with envisaging the cap and trade system as an architecture encompassing all gases, sectors, economic actors, and governments is that the focus remains on securing a traded ton of carbon that is precisely measured, whereas the core challenge is to curtail future emissions from quickly expanding infrastructures where the counterfactual baselines are impractical to measure. The cap and trade system misses opportunities for accruing mutual benefits of climate and development actions that relate primarily to these new infrastructures. The system will merely polarizes the debate on sharing the burden of carbon abatement rather than on mainstreaming the climate actions with development agenda. There should be concern about the constraint on development that a cap and trade system would bring.

There are mechanisms through which climate policies can exert a leverage effect on development that are absent in the cap and trade scheme. A mix of price signals, capital inflows, and technology transfers could be generated by carbon trading 
systems, but most important is institutional design by which revenues from carbon trading can be directed to removing obstacles to development and integrated into development policies. The configurations for such integration might vary, but in any case require a bottom-up design for facilitating a coordination of diverse initiatives and cost-effective and welfare-maximizing actions for mutual benefits vis-à-vis the development and carbon abatement objectives.

The nature of problem makes it neither politically feasible nor economically prudent to start from a full-fledged "grand architecture" nor to rely only on selforganizing processes such as the Madisonian approach (Victor et al. 2005) that set ambitious but nonbinding goals and do not generate the credible and stable policy signals such as could secure carbon saving investment in developing infrastructures.

The way out is not to dismiss the Kyoto Protocol, though it was ratified by overwhelming majority countries, but to re-interpret it by inverting the climate centric view that has prevailed so far. The technical instruments of inversion would involve the diversification of pledges, nonbinding commitments, safety valves, voluntary agreements in some key sectors of the world industry, re-design of the CDM in the direction of infrastructures programs. All these tools can be aligned to assemble a set of initiatives that will not result in a fragmentation of effort. But the challenge will be the many linkages of energy security, local environment issues, debt traps or social dualism, and reshaping of international funding and overseas aid that need to be recognized. The climate regime should be part and parcel of Pareto-improving policies 
that seek beneficial exchange in the globalization of economies and to narrow the North-South divide (Stiglitz 1998).

\section{References}

Agarwal, A. and Narain, S. 1991. Global Warming in an Unequal World, a Case of Environmental Colonialism. Center for Science and Environment, Delhi.

Bodansky, D. 2001. Bonn voyage. Kyoto's uncertain revival. The National Interest, Fall 2001. pp.45-55.

Bodansky, D. 2003. Climate commitments, assessing the options. In Beyond Kyoto, Advancing the International Effort against Climate Change. Pew Center on Global Climate Change, Washinton, DC. pp.37-59.

Brandt, W. 1980. Nord-Sud: Un Programme de survie. Rapport de la commission indépendante sur les problèmes de développement international. OECD, Paris.

Burton, M. 1985. Implementation of the EC milk quota. European Review of Agricultural Economics 12(4): 461-71.

Carter, A. P., W. Leontieff, and P. Petri. 1976. The Future of the World Economy. Department of Economic and Social Affairs. United Nations, New York. 
Chandler, W, R. Schaffer, Z. Dadi, P. R. Shukla, F. Tudela, O. Davidson, and S. Alpan-Atamar. 2002. Climate Change Mitigation in Developing Countries. Report. Pew Center on Global Climate Change, Washington, DC.

Chichilnisky, G., and G. Heal. 2000. Environmental Markets: Equity and Efficiency. New York: Columbia University Press.

Claussen, E., and L. Mc Neilly. 1998. Equity and Global Climate Change: The Complex Elements of Global Fairness. Pew Center on Global Climate Change, Washington, DC.

CMIE (Center for Monitoring Indian Economy). 2003. Energy. Center for Monitoring Indian Economy. Mumbai.

Cooper, R. (1998), “Toward a Real Global Warming Treaty.”, Foreign Affairs, 77(2), 6679.

Den Elzen, M., M. Berk, M. Schaeffer, J. Olivier, C. Hendricks and B. Metz (1999), The Brazilian proposal and other options for international burden sharing : an evaluation of methodological and policy aspects using the FAIR model, RIVM report $\mathrm{N}^{\circ} 728001011$, Bilthoven.

Fay M., Yepes F. (2003), Investing in infrastructure: what is needed from 2000 to 2010. World Bank Research Working Paper 3102.

Garg, A., Shukla, P.R., Ghosh, D., Kapshe, M., and Nair, Rajesh (2003). "Future GHG and Local Emissions for India: Policy Links and Disjoints”, Mitigation and Adaptation Strategies for Global Change, Vol. 8, No. 1 71-92. 
G7 and China. 1997. Position paper of the group G7 and China on the mechanism of the Kyoto Protocol for the second meeting of the contact group on mechanism. 2p.

Garg, A., P. R. Shukla, D. Ghosh, M. Kapshe, and R. Nair. 2003. Future GHG and local emissions for India: Policy links and disjoints. Mitigation and Adaptation Strategies for Global Change 8 (1): 71-92.

Ghersi, F., J. C. Hourcade, and P. Criqui. 2003. Viable responses to the equityresponsibility dilemna: a consequentialist view. Climate Policy 3 (S1): S115-33.

Godard, O. 2000. Sur l'éthique, l'environnement et l'économie : la justification en question. Cabier du Laboratoire d'Econométrie de l'Ecole Polytechnique: 513.

Goulder, L. 2004. Efficiency costs of meeting industry-distributional constraints under environmental permits and taxes (with A. Lans Bovenberg and D. J. Gurney). Rand Journal of Economics, forthcoming,

Groenenberg, H., D. Phylipsen, and K. Blok. 2000. Differenciating commitments world wide: Global differenciation of GHG emissions reductions based on the Triptych approach—a preliminary assessment. Energy Policy 29(12): 1007-30.

Grubb, M. 1989. The Greenhouse Effect : Negotiating Targets. Royal Institute for International Affairs, London.

Heller, T. C., and P. R. Shukla. 2003. Development and climate-Engaging developing countries. In Beyond Kyoto: Advancing the International Effort against 
Climate Change. Pew Center on Global Climate Change, Washington, DC. pp.111-140.

Heller T.C., Shukla P.R. (2004), Financing the Climate-friendly Development Pathway: with Illustrative Case Studies from India, Workshop on "Development and Climate" organized by RIVM, The Netherlands and Indian Institute of Management, Abmedabad (IIMA), New Delhi, September.

Helioui, K. 2002. On the dynamic efficiency and environmental integrity of GHG tradable quotas. In J. Albrecht, ed., Instruments for Climate Policy: Limited versus Unlimited Flexibility. Aldershot, UK: Edward Elgar, ch. 11.

INGENUE Team. 2005. Scenarios for global ageing: An investigation with the INGENUE 2 world model. Working paper. 42p.

International Energy Agency (IEA). 2000, 2002, 2003. World Energy Outlook. OECD, Paris.

IPCC. 1995. Climate Change 1995: Mitigation. Contribution of Working Group III to the Second Assessment Report. Cambridge: Cambridge University Press Jacoby, H. D., R. Schlamensee, and I. S. Wing. 1999. Toward a useful architecture for climate change negotiations. Report 49. Joint Program on the Science and Policy of Global Change, Massachusetts Institute of Technology.

Jacoby, J. 2005. Climate favela: Regime building with no architect. Post 2012 climate policy: architectures and participation scenarios. FEEM, Venice. 
Jaffe, A. B., and R. N. Stavins. 1994. The energy paradox and the diffusion of conservation technology. Resource and Energy Economics 16: 91-122.

Jansen, J. C., J. J. Battjes, J. P. M. Sijm, C. H. Volkers, and J. R. Ybema. 2001. The multi-sector convergence approach: A flexible framework for negotiating global rules for national greenhouse gas emissions mitigation targets. CICERO Working paper 2001:4, ECN-C—01-007.

Joskow, P., R. Schmalensee, and E. M. Bailey. 1999. The market for sulfur dioxide emissions. American Economic Review 88(4): 669-85.

Kapshe, M, P. R. Shukla, and A. Garg. 2003. Climate change impacts on infrastructure and energy systems. In P. R. Shukla, S. Subodh, N. H.. Ravindranath, A.. Garg, and S. Bhattacharya, eds., Climate Change and India: Vulnerability Assessment and Adaptation. Hyderabad: Universities Press (India) Pvt Ltd.

Kopp, R., R. D. Morgenstern, and W. A. Pizer. 2000. Limiting cost, assuring effort, and encouraging ratification: Compliance under the Kyoto Protocol. CIRED/RFF Workshop on Compliance and Supplemental Framework <http://www.weathervane.rff.org/features/parisconf0721/summary.html>.

KRCL. 1999. Treatise on Konkan railway. Konkan Railway Corporation Ltd., Mumbai. 
Lecocq, F., and R. Crassous. 2003. International climate regime beyond 2012. Are quota allocation rules robust to uncertainty? World Bank Policy Research working paper 3000. World Bank, Washington, DC.

Mathy, S., and J. C. Hourcade, and C. de Gouvello. 2001. Clean development mechanism: leverage for development? Climate Policy 1 (2): 251-68.

Menon-Choudhary, D, P. R. Shukla, T. Nag, and D. Biswas. 2004. Electricity reforms, firm level responses and environmental implications. In J. Ruet, and P. Kalra, eds., Studies on Electricity Reforms in India. New Delhi: Manohar Publishers, forthcoming.

Meyer, A. 2000. Contraction and convergence. The global solution to climate change, Schumacher briefing 5, The Schumacher Society, Bristol.

Mitra, A. P., D. Kumar, K. Rupa Kumar, Y. P. Abrol, K. Naveen, M. Velayuthan, and S. W. A. Naqvi. 2002. Global change and biogeochemical cycles: The South Asia region. In Tyson, P.D., Fuchs R, Fu C, Lebel L, Mitra AP, Odada E, Perry J, Steffen W, Virji H (Eds.), The Earth System: Global Regional Linkages. Berlin: Springer. pp.75-108

Nair, R., P. R. Shukla, M. Kapshe, A. Garg, and A. Rana. 2003. Analysis of long-term energy and carbon emission: Scenarios for India. Mitigation and Adaptation Strategies for Global Change 8: 53-69.

Neumayer, E. 2002. Can natural factors explain any cross-country differences in carbon dioxide emissions? Energy Policy 30: 7-12. 
Nordhaus, W. D. 1994. Managing Commons. Cambridge: MIT Press.

Pandey, R., and P. R. Shukla. 2003. Methodology for exploring co-benefits of $\mathrm{CO}_{2}$ and $\mathrm{SO}_{2}$ mitigation policies in India using $\mathrm{AIM} /$ end use model. In M. Kainuma; Y. Matsuoka, and T. Morita, eds., Climate Policy Assessment: AsiaPacific Integrated Modeling. Berlin: Springer. Pp.113-122.

Philibert, C., and J. Pershing. 2002. Beyond Kyoto, Energy Dynamics and Climate Stabilisation. OECD/AIE, Paris.

Planning Commission. 2002. Report of the Committee on India Vision 2020. Government of India, New Delhi.

Phylipsen, G. J. M., J. W. Bode, and K. Blok. 1998. A triptych approach to burden differentiation: GHG emissions in the European bubble. Energy Policy 26 (12): 929-43.

Quirion, P., and J.-C. Hourcade. 2004. Does the $\mathrm{CO}_{2}$ emission trading directive threaten the competitiveness of European industry? Quantification and comparison to exchange rates fluctuations. European Association of Environmental and Resource Economists Annual Conference, Budapest, June.

Roberts, M. I., and M. Spence. 1976. Effluent charges and licences under uncertainty. Journal of Public Economics 5: 193-208.

Sagar, A. D. 2005. Alleviating energy poverty for the world's poor. Energy Policy 33: $1367-72$. 
Schlessinger, J. R. 1989. Energy and geopolitics in the 21st century. World Energy Conference 14th Congress Montreal, Quebec.

Shukla, P. R., T. Heller, D. Victor, D. Biswas, T. Nag, and A. Yajnik. 2004. Electricity Reforms in India: Firm Choices and Emerging Generation Markets. New Delhi: Tata McGraw-Hill.

Sterner, T. 2002. Policy instruments for environmental and natural resource management. RFF, World Bank, SIDA, Washington, DC.

Stiglitz, J. E. 1998. The private uses of public interests: Incentives and institutions. Journal of Economic Perspectives 12(2): 3-22.

Tinbergen, J. 1976. Reshaping the International Order. Report to the Club of Rome. New York: Duttow.

UNFCCC. 1997. Proposed elements of a protocol to the United Nations framework. Convention on Climate Change. Presented by Brazil in response to the Berlin Mandate, AGBM/1997/misc.1/add.3.

Victor, D.G., J. House, and S. Joy. 2005. A Madisonian approach to climate policy. Science 309 (September).

Notes 
1. The vital lead of Myrdal's ‘Asian Drama', Sen's early contributions, R. Dumont's 'Afrique Noire est mal partie', the UNCTAD group (R. Prebisch) was to raise questions both about the trickling down of the Western economic growth to developing countries (Rostow) and about the replication in these countries of the socialist primitive capital accumulation.

2. For a detailed description of the methodology refer to Mathy et al. (2001).

3. This region comprising of Bangladesh, Bhutan, India, Maldives, Nepal, Pakistan and Sri Lanka holds nearly a quarter of world population

4. to minimize market powers and the strategic use of carbon trading by governments, one important addition to the Marrakech accord would be to impose that all imports and exports between governments take place through transparent auctioning on a state regulated clearinghouse.

5. To this respect the European Carbon Trading System is not a small scale model of an international trading system; it is one specific modality adopted by some governments to meet their targets

6. a floor price of carbon can provide an additional hedge against deflated carbon prices.

7. Chinese per capita growth rate was 2\% in 1990 and 13\% in 1992; Argentina experienced a $-8 \%$ in 1989 and a 9\% in 1991. 